\title{
Vitrification of Immature Bovine Oocytes by the Microdrop Method
}

\author{
Dong-Hoon KIM ${ }^{1) *}$, Hyo-Suk PARK ${ }^{1,2) *}$, Se-Woong KIM ${ }^{1)}$, In-Sun HWANG ${ }^{1)}$, \\ Byoung-Chul YANG ${ }^{1)}$, Gi-Sun IM ${ }^{1)}$, Hak-Jae CHUNG ${ }^{1)}$, Hwan-Woo SEONG ${ }^{1}$, \\ Seung-Joo $\mathrm{MOON}^{2)}$ and Boh-Suk YANG ${ }^{1)}$
}

1)Animal Biotechnology Division, National Institute of Animal Science, 564 Omockchun-dong, Kwonsun-gu, Suwon 441-706 and ${ }^{2)}$ Department of Animal Science and Biotechnology, Chonnam National University, 300 Yongbong-dong, Buk-gu, Kwangju 500-757, Korea

\begin{abstract}
This study was conducted to determine the optimal vitrification conditions for immature bovine oocytes using the microdrop method. In experiment 1 , the optimal pre-equilibration period for microdrop vitrification was examined. The maturation rate of vitrified oocytes with a 3 min first preequilibration period $(41.1 \%)$ was higher than that of vitrified oocytes with a 0 min first preequilibration period $(21.4 \%)$, and the values of those with a $1(33.9 \%)$ or $5 \mathrm{~min}(27.4 \%)$ first preequilibration period were intermediate. The value for a $1 \mathrm{~min}$ second pre-equilibration period $(44.4 \%)$ was significantly higher $(\mathrm{P}<0.05)$ than those for a $0.5(28.6 \%)$ and 2 min $(21.4 \%)$ second preequilibration period. In experiment 2 , the distribution of microtubules in matured oocytes was investigated. There was no difference among the first pre-equilibration times in terms of the rates of normal spindles in vitrified oocytes. However, this value was significantly higher $(\mathrm{P}<0.05)$ in the 1 min group $(52.8 \%)$ compared with the $0.5(16.7 \%)$ and 2 min groups $(12.3 \%)$. In experiment 3 , we investigated the developmental capacity of immature bovine oocytes vitrified under optimal preequilibration conditions ( $3 \mathrm{~min}$ and $1 \mathrm{~min}$ for the first and second pre-equilibrations, respectively). Although the total fertilization rates were significantly lower $(\mathrm{P}<0.05)$ in the vitrified oocytes $(65.6 \%)$ compared with the control oocytes $(92.4 \%)$, there was no difference in the rate of normal fertilization $(2 \mathrm{PN})$ between the vitrified $(78.6 \%)$ and control $(82.0 \%)$ oocytes. Cleavage and blastocyst rates were significantly lower $(\mathrm{P}<0.05)$ in vitrified oocytes $(55.7$ and $2.3 \%)$ than in control oocytes $(84.4$ and $34.7 \%)$. Thus, these results indicated that immature bovine oocytes can survive after microdrop vitrification and subsequently can be cultured to mature oocytes capable of undergoing fertilization in vitro and developing into blastocysts.
\end{abstract}

Key words: Bovine, Immature oocyte, Microdrop, Pre-equilibration time, Vitrification

(J. Reprod. Dev. 53: 843-851, 2007)

C ryopreservation of oocytes is important for establishment and maintenance of genetic banks. If oocytes could be successfully cryopreserved and/or vitrified, timing of in vitro maturation, in vitro fertilization, and nuclear

Accepted for publication: March 21, 2007

Published online: April 26, 2007

*These authors contributed equally to this work.

Correspondence: D-H. Kim (e-mail: kimdhhj@hanmail.net) transfer would be more flexible. This would facilitate maintenance of frozen oocyte banks for advancement of genetic improvement and increase the availability of materials for basic research.

Some researchers have reported successful vitrification of unfertilized oocytes from the mouse [1-3], human [4], and bovine [5]. Until recently, attention has been focused on cryopreservation of mature oocytes; however, this process induces 
disorganization of the spindle in oocytes at this stage and results in disruption of chromosomes, microtubules, and microfilaments. Immature oocytes, on the other hand, do not have an organized meiotic spindle. Therefore, cryopreservation at this stage may be an alternative approach [6]. Blastocysts [7], pregnancies [8, 9], and calves $[6,10]$ have been produced from frozen immature bovine oocytes. However, the rates of subsequent fertilization and development are much lower in these cases than in those obtained using fresh oocytes. An insufficient cooling rate during oocyte vitrification is believed to be one of the obstacles in vitrification [11]. In order to overcome this problem, methods using electron microscopy (EM) grids [12], cryoloops [13], nylon mesh [14], and open-pulled straws (OPS) [6] have been employed. These methods enable use of a minimal volume of freezing medium and a very high cooling rate that permits rapid traversal of the dangerous temperature zone, corresponding to chilling sensitivity. The simplest way to establish this contact is by directly dropping oocytes into liquid nitrogen (the microdrop method). This method was first proposed by Landa and Tepla [15] for mouse embryos; it was then successfully used for bovine embryos, zygotes, and oocytes [16-18]. However, use of the microdrop method for vitrification of immature bovine oocytes has not been reported thus far.

To determine the optimal conditions for vitrification of bovine immature oocytes using the microdrop method, we examined the effects of equilibration time on the survival and maturation of vitrified oocytes, distribution of microtubules, and microfilaments in matured oocytes after vitrification. We also examined the developmental ability of the above-mentioned vitrified immature oocytes after in vitro fertilization.

\section{Materials and Methods}

\section{Collection of immature oocytes}

Bovine ovaries obtained from a slaughterhouse were transported in saline at $37 \mathrm{C}$ to the laboratory. Cumulus-oocyte complexes (COCs) were aspirated from 2- to 7-mm antral follicles and washed three times with HEPES-buffered TCM 199 supplemented with $10 \%$ fetal bovine serum (FBS; Gibco-BRL, Carlsbad, CA, USA). COCs with a uniform ooplasm and at least one layer of compact cumulus cells were selected for the experiment.

\section{Vitrification and warming}

Immature bovine oocytes were vitrified using the microdrop method. COCs were equilibrated in a solution of $10 \%$ ethylene glycol (EG) and 10\% dimethyl sulfoxide (DMSO) in HEPES-buffered TCM 199 supplemented with 20\% FBS (H-TCM) and then transferred to a vitrification solution of 20\% EG, 20\% DMSO and 0.5 M sucrose in H-TCM. Pre-equilibration procedures were performed at room temperature. A total of 5 to $10 \mathrm{COCs}$ in vitrification solution $(2-3 \mu \mathrm{l})$ were dropped into liquid nitrogen using a glass micropipette. The microdrops were transferred into a 2 ml-cryotube and preserved in liquid nitrogen. For warming, a cryotube containing the oocytes was held in the air for $10 \mathrm{sec}$, and microdrops (containing the oocytes) were sequentially transferred into H-TCM containing $0.5,0.25,0.125$, or $0 \mathrm{M}$ sucrose at $1 \mathrm{~min}$ intervals at $39 \mathrm{C}$.

\section{In vitro maturation (IVM)}

COCs that showed homogeneous cytoplasm, an intact plasma membrane, and a zona pellucida were considered to have survived the vitrification process. These COCs were transferred to maturation medium after warming. The maturation medium was TCM 199 supplemented with $10 \%$ FBS, $1 \mu \mathrm{g} / \mathrm{ml}$ FSH (Folltropin-V; Bioniche, Belleville, ON, Canada) and $1 \mu \mathrm{g} / \mathrm{ml}$ estradiol-17 $\beta$. The COCs were cultured in maturation medium under mineral oil at $39 \mathrm{C}$ in a humidified atmosphere of $5 \% \mathrm{CO}_{2}$ in air for $24 \mathrm{~h}$.

\section{In vitro fertilization (IVF)}

A single straw of semen containing sperm was thawed in a water bath set at $37 \mathrm{C}$. The contents were deposited on a $45 \% / 90 \%$ Percoll gradient (Sigma, St. Louis, MO, USA) in a 15-ml centrifuge tube and then centrifuged at 1,500 rpm for $20 \mathrm{~min}$. After centrifugation, the supernatant was aspirated, the pellet was resuspended in $5 \mathrm{ml}$ of Sperm-TALP (with $6 \mathrm{mg} / \mathrm{ml}$ BSA) [19], and then it was centrifuged again at 1,200 rpm for $10 \mathrm{~min}$. The supernatant was discarded, and the formed pellet was diluted with Sperm-TALP. For fertilization, matured oocytes were washed 2 times with FertTALP [20]. After washing, groups of 10 matured oocytes were transferred into $50 \mu$ d droplets of Fert- 


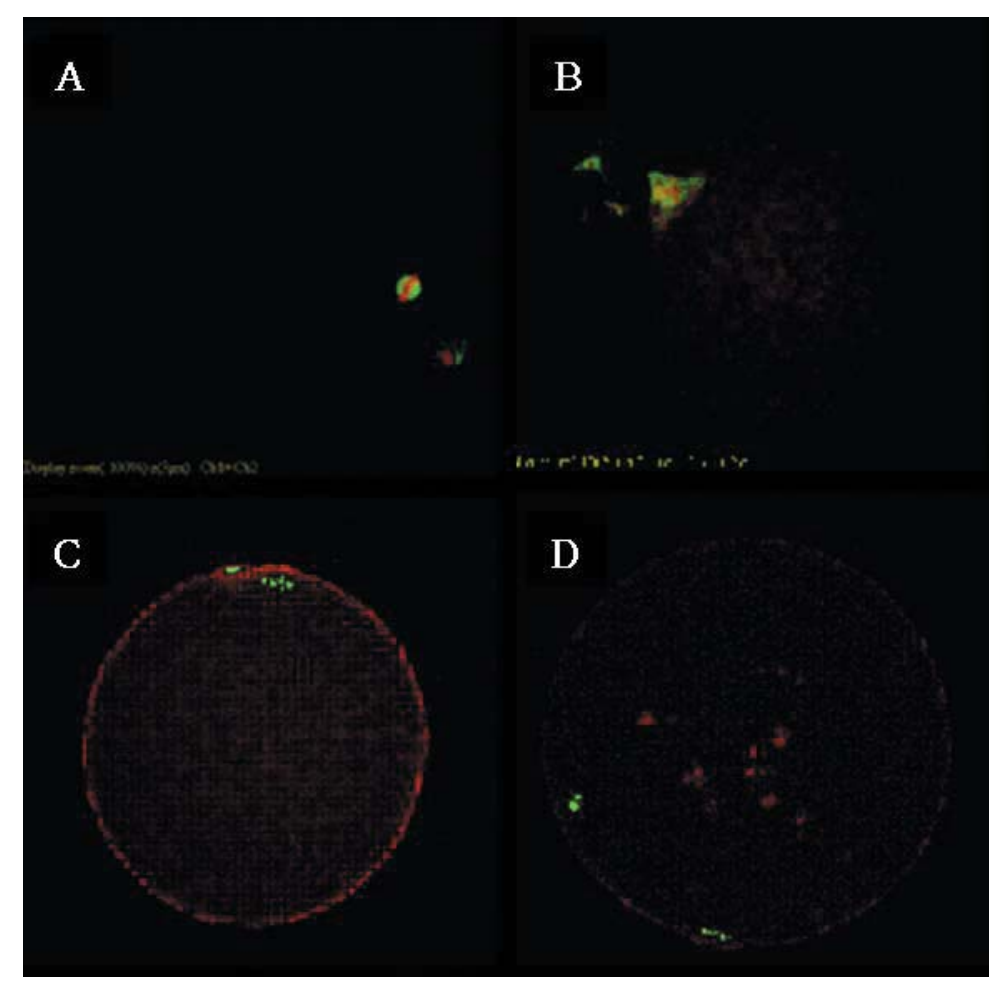

Fig. 1. Immunofluorescence images of microtubules, chromosomes and microfilaments. A and B show the typical normal microtubule shape of an oocyte and abnormal pattern of an oocyte, respectively. $\mathrm{C}$ and D show the normal microfilament shape of an oocyte and abnormal shape of an oocyte, respectively.

TALP supplemented with $6 \mathrm{mg} / \mathrm{ml}$ fatty acid-free BSA (FAF-BSA; Sigma), $10 \mu \mathrm{g} / \mathrm{ml}$ heparin (Sigma) and PHE (18.2 mM penicillamine, $9.1 \mathrm{mM}$ hypotaurine and $1.8 \mathrm{mM}$ epinephrine). Subsequently, the sperm suspension was added to the droplets of Fert-TALP containing oocytes (final concentration: $1 \times 10^{6} \mathrm{sperm} / \mathrm{ml}$ ). The oocytes and spermatozoa were co-incubated for 20 to $24 \mathrm{~h}$.

At $18 \mathrm{~h}$ after insemination, a portion of the oocytes was fixed and stained with Hoechst 33342 $(2.5 \mu \mathrm{g} / \mathrm{ml})$ and observed under a fluorescence microscope (excitation $347 \mathrm{~nm}$ and emission 483 $\mathrm{nm})$ to examine the fertilization rate.

\section{In vitro culture (IVC)}

At 20 to $24 \mathrm{~h}$ post-insemination, the cumulus cells of oocytes were removed by repeated pipetting. The presumptive zygotes were cultured in CR-2 medium [21] supplemented with $3 \mathrm{mg} / \mathrm{ml} \mathrm{FAF-}$ BSA for 3 day and then further cultured in CR-2 medium supplemented with 5\% FBS and $1.5 \mathrm{mg} /$ ml FAF-BSA for 4 days. The culture conditions were set to $39 \mathrm{C}$ in a humidified atmosphere of $5 \%$ $\mathrm{O}_{2}, 5 \% \mathrm{CO}_{2}$ and $90 \% \mathrm{~N}_{2}$.

\section{Immunocytochemical staining}

Microtubules and chromosomes of the matured oocytes in each treatment were detected by indirect immunocytochemical techniques. The oocytes were permeabilized in modified Buffer M $(25 \%$ glycerol, $50 \mathrm{mM} \mathrm{KCl}, 0.5 \mathrm{mM} \mathrm{MgCl} 2,0.1 \mathrm{mM}$ ethylenediaminetetraacetic acid, $1 \mathrm{mM} \beta$ mercaptoethanol, $50 \mathrm{mM}$ imidazole, $3 \%$ Triton $X$ 100 and $25 \mathrm{mM}$ phenylmethylsulfonyl fluoride) for $20 \mathrm{~min}$, fixed in methanol at $-20 \mathrm{C}$ for $10 \mathrm{~min}$, and stored in PBS containing $0.02 \%$ sodium azide and $0.1 \%$ BSA for 2 to 7 days at $4 \mathrm{C}$. The fixed oocytes were incubated for $90 \mathrm{~min}$ at $39 \mathrm{C}$ with a 1:100 dilution of anti- $\alpha$-tubulin antibody in PBS after several washes with PBS containing $0.5 \%$ Triton X100 and $0.5 \%$ BSA. The oocytes were then incubated in a blocking solution $(0.1 \mathrm{M}$ glycine, $1 \%$ 
calf serum, $0.01 \%$ Triton $\mathrm{X}-100,1 \%$ powdered milk, $0.5 \%$ BSA and $0.02 \%$ sodium azide) at $39 \mathrm{C}$ for $1 \mathrm{~h}$. Blocking was followed by incubation with a fluorescein isothiocyanate (FITC)-labeled goat antimouse antibody (Sigma). DNA was fluorescently detected by exposure to $10 \mu \mathrm{g} / \mathrm{ml}$ propidium iodide (Sigma) for $1 \mathrm{~h}$. The stained oocytes were then mounted under a coverslip with anti-fade mounting medium (Vectashield; Vector Lab, Burlingame, CA, USA) to delay photobleaching.

For microfilament immunostaining, oocytes were fixed with 3.7\% paraformaldehyde in PBS for at least $2 \mathrm{~h}$. After fixation, the oocytes were treated with $1 \%$ Triton X-100 in PBS for $2 \mathrm{~h}$ at $39 \mathrm{C}$ or overnight at $4 \mathrm{C}$ and then blocked in PBS containing $150 \mathrm{mM}$ glycine for $30 \mathrm{~min}$. After washing, the oocytes were stained with $10 \mathrm{IU} / \mathrm{ml}$ rhodamine-phalloidin (Molecular Probes, Eugene, OR, USA) for $1 \mathrm{~h}$ at $39 \mathrm{C}$ in PBS-Tween 20. After washing, the oocytes were treated in PBS-Tween 20 solution for $2 \mathrm{~h}$. The oocytes were then stained with $100 \mathrm{nM}$ Yo-Pro-1 iodide (Molecular Probes) for $10 \mathrm{~min}$. Finally, they were mounted under a coverslip with anti-fade mounting medium. The slides were examined using laser scanning confocal microscopy.

Spindle and chromosome configuration were assessed using the criteria described in Cai et al. [22]. Spindle configuration in metaphase II oocytes was regarded as morphologically normal if a barrel-shaped structure with slightly pointed poles was formed by organized microtubules traversing from one pole to another. The chromosomal configuration was regarded as normal if the chromosomes were arranged on a compact metaphase plate at the equator of the structure. A normal spindle indicates that the spindle configuration, spindle microtubules, and chromosomes were all normal (Fig. 1A). Abnormalities included disorganization of microtubules and chromosomes displaced from the plane of the metaphase plate (Fig. 1B).

The cytoskeletal actin band was considered to be normal if an evenly stained layer of actin was observed immediately beneath the plasma membrane (Fig. 1C). Changes in the appearance of the cortical actin band were classified as abnormal if diffuse or discontinuous actin staining patterns were observed (Fig. 1D).

\section{Detection of apoptotic cells}

Day 7 blastocysts were fixed in $4 \%$ paraformaldehyde in PBS for $1 \mathrm{~h}$ at room temperature. The embryos were washed twice in PBS containing 0.3\% polyvinylpyrrolidone (PVPPBS). The fixed embryos were permeabilized with $0.5 \%$ Triton $X-100$ in PBS for 30 min at room temperature. The blastocysts were washed twice in PVP-PBS, placed into $5 \mu$ drops of TMR redconjugated TUNEL reagent (Roche, Mannheim, Germany), and incubated in the dark at $39 \mathrm{C}$ for $1 \mathrm{~h}$. They were subsequently washed with PBS containing $0.5 \%$ Triton $\mathrm{X}-100$ for $5 \mathrm{~min}$ and then PVP-PBS. For counterstaining, the blastocysts were incubated in PBS containing Hoechst $33342(20 \mu \mathrm{g} /$ $\mathrm{ml}$ ) for $30 \mathrm{~min}$ at room temperature in the dark. After washing twice in PVP-PBS, the blastocysts were mounted with anti-fade medium. Evaluation was performed on a slide glass, and the blastocysts were visualized using laser scanning confocal microscopy.

\section{Experimental designs}

In experiment 1 , immature bovine oocytes were pre-equilibrated in vitrification solution using various first pre-equilibration periods $(0,1,3$ or 5 min) followed by a second pre-equilibration period of $30 \mathrm{sec}$ prior to vitrification in order to determine the optimal first pre-equilibration period. Immature bovine oocytes were pre-equilibrated in vitrification solution for $3 \mathrm{~min}$ followed by another $0.5,1$ or 2 min of pre-equilibration prior to vitrification in order to determine the optimal second pre-equilibration period. After warming, the survival and maturation rates of the treatment groups were compared.

In experiment 2, immature bovine oocytes were pre-equilibrated using various first and second preequilibration periods prior to vitrification in the same manner as in experiment 1 . The rewarmed oocytes were allowed to undergo in vitro maturation for $24 \mathrm{~h}$. The distribution of microtubules and microfilaments in the matured oocytes was then compared among the treatment groups.

In experiment 3, immature bovine oocytes were vitrified following determination of an optimal preequilibration combination. After in vitro fertilization, the developmental capacity of the vitrified oocytes was compared with that of fresh oocytes. 
Table 1. Effect of the first pre-equilibration period on maturation of vitrified immature bovine oocytes

\begin{tabular}{ccccc}
\hline $\begin{array}{c}\text { Time } \\
(\mathrm{min})\end{array}$ & $\begin{array}{c}\text { Vitrified } \\
n\end{array}$ & $\begin{array}{c}\text { Morphologically } \\
\text { survived } n(\%)\end{array}$ & $\begin{array}{c}\text { survived } \\
n(\%)^{*}\end{array}$ & $\begin{array}{c}\text { Matured } \\
n(\%)^{*, * *}\end{array}$ \\
\hline $\begin{array}{c}\text { Control } \\
0\end{array}$ & 52 & $52(100)^{\mathrm{a}}$ & $37(71.2)^{\mathrm{a}}$ \\
1 & 92 & $56(60.9)^{\mathrm{a}}$ & $25(44.4)^{\mathrm{b}, \mathrm{c}}$ & $12(21.4)^{\mathrm{b}, \mathrm{c}}$ \\
3 & 83 & $62(74.7)$ & $37(59.7)^{\mathrm{b}}$ & $21(33.9)^{\mathrm{b}, \mathrm{d}}$ \\
5 & 94 & $76(80.9)^{\mathrm{b}}$ & $52(68.4)^{\mathrm{b}, \mathrm{d}}$ & $30(41.1)^{\mathrm{b}, \mathrm{d}}$ \\
\hline
\end{tabular}

ab, cd Significant differences within the same column $(\mathrm{P}<0.05)$. *Survival of oocytes was evaluated after 24 $\mathrm{h}$ of in vitro maturation. ${ }^{* *}$ Maturation of oocytes was defined by the presence of the first polar body.

Table 2. Effect of the second pre-equilibration period on maturation of vitrified immature bovine oocytes

\begin{tabular}{ccccc}
\hline $\begin{array}{c}\text { Time } \\
(\min )\end{array}$ & $\begin{array}{c}\text { Vitrified } \\
n\end{array}$ & $\begin{array}{c}\text { Morphologically } \\
\text { survived } n(\%)\end{array}$ & $\begin{array}{c}\text { Survived } \\
n(\%)^{*}\end{array}$ & $\begin{array}{c}\text { Matured } \\
n(\%)^{*, * *}\end{array}$ \\
\hline Control & & 76 & $76(100)^{\mathrm{a}}$ & $46(60.5)^{\mathrm{a}}$ \\
0.5 & 98 & $70(71.4)^{\mathrm{a}}$ & $48(68.6)^{\mathrm{b}, \mathrm{c}}$ & $20(28.6)^{\mathrm{b}}$ \\
1 & 94 & $81(86.2)^{\mathrm{b}}$ & $70(86.4)^{\mathrm{b}, \mathrm{d}}$ & $36(44.4)^{\mathrm{c}}$ \\
2 & 97 & $70(72.2)^{\mathrm{a}}$ & $55(78.6)^{\mathrm{b}}$ & $15(21.4)^{\mathrm{b}, \mathrm{d}}$ \\
\hline
\end{tabular}

$\mathrm{ab}, \mathrm{cd}$ Significant differences within the same column $(\mathrm{P}<0.05)$. *Survival of oocytes was evaluated after $24 \mathrm{~h}$ of in vitro maturation. ${ }^{* *}$ Maturation of oocytes was defined by the presence of the first polar body.

\section{Statistical analysis}

Significant differences among treatment groups in each experiment were determined using the General Linear Models procedure and Duncan's multiple range test of Statistical Analysis System. Differences with values of $\mathrm{P}<0.05$ were considered to be statistically significant.

\section{Results}

\section{Pre-equilibration conditions for vitrification (Experiment 1)}

Table 1 shows the survival and maturation rates of vitrified oocytes following various first preequilibration periods before vitrification. After $24 \mathrm{~h}$ of culture, the survival rates were 68.4 and $73.8 \%$ for 3 and $5 \mathrm{~min}$, respectively, which were significantly higher rates $(\mathrm{P}<0.05)$ compared with the rate obtained for $0 \mathrm{~min}(44.4 \%)$. The rate of immature oocytes reaching the mature stage for a first pre-equilibration period of $3 \mathrm{~min}(41.1 \%)$ was higher than that for $0 \mathrm{~min}(21.4 \%)$, and the values for $1 \mathrm{~min}(33.9 \%)$ and $5 \mathrm{~min}(27.4 \%)$ were intermediate. Table 2 shows the survival and maturation rates of oocytes following various second pre-equilibration periods in the vitrification solution prior to vitrification. Based on the obtained results (Table 1), the first pre-equilibration period used in this experiment was $3 \mathrm{~min}$. After 24 $\mathrm{h}$ of culture, the survival rate was $86.4 \%$ for the 1 min group, which was a significantly higher rate $(\mathrm{P}<0.05)$ compared with the $0.5 \mathrm{~min}$ group $(68.6 \%)$. The maturation rate of vitrified immature oocytes was $44.4 \%$ for the 1 min group, which was a significantly higher rate $(\mathrm{P}<0.05)$ compared with the 2 min group $(21.4 \%)$. These results suggest that the most effective combination of pre-equilibration periods for vitrification of immature bovine oocytes using the microdrop method is a 3 min first preequilibration followed by a $1 \mathrm{~min}$ second preequilibration.

\section{Microtubule and microfilament changes in vitrified} bovine immature oocytes (Experiment 2)

Fig. 2 shows the details observed in for the spindle configurations of vitrified oocytes following various first pre-equilibration periods before vitrification. The spindle configurations observed in the vitrified oocytes pre-equilibrated for $3 \mathrm{~min}(16.3 \%, 7 / 43)$ and $5 \mathrm{~min}(25.0 \%, 9 / 36)$ showed a tendency to exhibit higher normality than those pre-equilibrated for $0 \mathrm{~min}(10.0 \%, 3 / 30)$ and 1 $\min (10.0 \%, 3 / 30)$. However, there were significant 


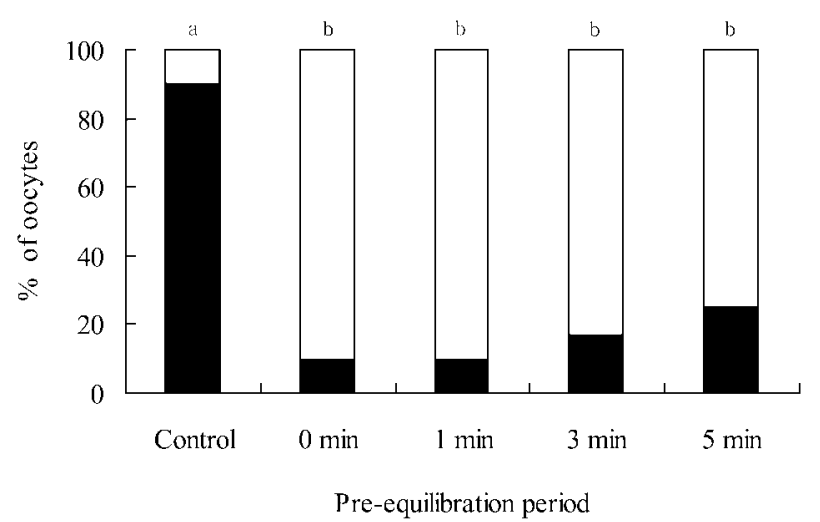

Fig. 2. Effect of the first pre-equilibration period on the microtubule normality of vitrified immature bovine oocytes. Bars represent the proportion of total oocytes observed in each category. Solid: normal. Open: abnormal. ${ }^{\text {ab: }} \mathrm{P}<0.05$.

differences $(\mathrm{P}<0.05)$ between oocytes with any combination of pre-equilibration period and control oocytes $(90.0 \%, 27 / 30)$ in terms of the rate of normal spindles in vitrified oocytes.

Fig. 3 shows the details observed for the spindle configuration of vitrified oocytes following various second pre-equilibration periods in vitrification solution prior to vitrification. The normal spindle rate for the $1 \mathrm{~min}$ group $(52.8 \%, 19 / 36)$ was significantly higher $(\mathrm{P}<0.05)$ than that of the $0.5 \mathrm{~min}$ $(16.7 \%, 6 / 36)$ and 2 min groups $(12.5 \%, 4 / 32)$ but was significantly lower $(\mathrm{P}<0.05)$ than that of the control group $(90 \%, 27 / 30)$. These results reconfirm that the most effective combination of pre-equilibration periods for vitrification of immature bovine oocytes using the microdrop method is a $3 \mathrm{~min}$ first pre-equilibration followed by a $1 \mathrm{~min}$ second pre-equilibration.

Immature bovine oocytes were vitrified following first pre-equilibration for $3 \mathrm{~min}$ and second pre-equilibration for $1 \mathrm{~min}$; the microfilament distribution of the matured oocytes after in vitro maturation was then analyzed. The results revealed that $82.9 \%(29 / 35)$ of the control oocytes and $60.0 \%(15 / 25)$ of the vitrified oocytes had a normal actin band.

\section{Developmental capacity of vitrified bovine immature} oocytes (Experiment 3)

After fertilization, the detailed status of the fertilized oocytes was visualized by fluorescence

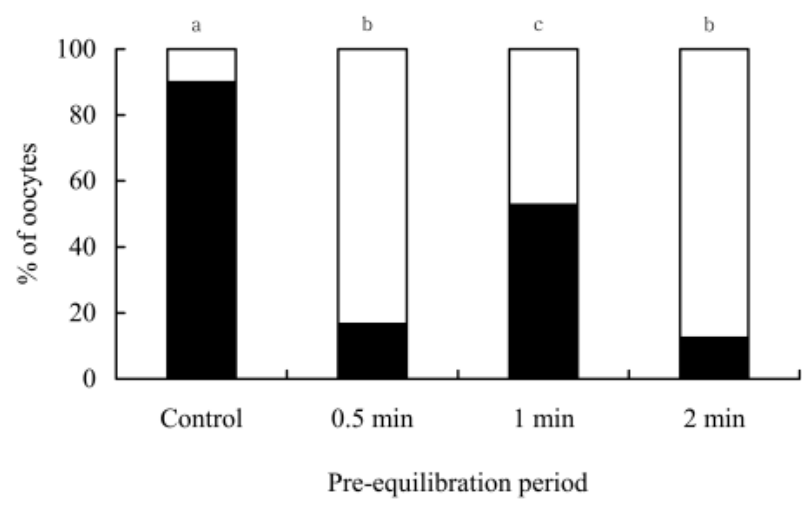

Fig. 3. Effect of the second pre-equilibration period on the microtubule normality of vitrified immature bovine oocytes. Bars represent the proportion of total oocytes observed in each category. Solid: normal. Open: abnormal. abc: $\mathrm{P}<0.05$.

staining. As shown in Table 3, the total fertilization rate of the vitrified oocytes $(65.6 \%)$ was significantly lower $(\mathrm{P}<0.05)$ than that of fresh oocytes $(92.4 \%)$. However, there was no significant difference in the rates of two pronuclei (2PN) oocytes (calculated using the number of fertilized oocytes; $82.0 \%$ for the control oocytes vs. $78.6 \%$ for the vitrified oocytes). The rate of polyspermy $(\geq 3 \mathrm{PN}$ ) was similar in the two group (control: $3.2 \%$ vs. vitrified: $4.7 \%$ ). As shown in Table 4 , the cleavage and blastocyst rates of the vitrified oocytes $(34.2$ and $1.9 \%)$ were significantly $(\mathrm{P}<0.05)$ lower than those of the control oocytes (83.3 and $45.9 \%$ ). The total cell number of blastocysts derived from vitrified oocytes $(84.3 \pm 25.8)$ was no different from that of blastocysts derived from control oocytes $(92.8 \pm 26.5)$. Although the number of apoptotic cells of blastocysts derived from vitrified oocytes $(4.8 \pm 2.9)$ was a little higher than that of blastocysts derived from control oocytes $(2.8 \pm 2.6)$, no significant differences were observed between the two groups.

\section{Discussion}

For several years, vitrification has been considered a promising option for bovine oocyte cryopreservation. However, despite successful results [23] and reports of numerous attempts [7, $24,25]$, the effectiveness of vitrification methods 
Table 3. Fertilization rates of immature bovine oocytes after vitrification

\begin{tabular}{cccccc}
\hline Treatment & $\begin{array}{c}\text { Examined } \\
n\end{array}$ & $\begin{array}{c}\text { Fertilized } \\
n(\%)\end{array}$ & $\begin{array}{c}1 \mathrm{PN} \\
n(\%)^{*}\end{array}$ & $\begin{array}{c}2 \mathrm{PN} \\
n(\%)^{*}\end{array}$ & $\begin{array}{c}\geq 3 \mathrm{PN} \\
n(\%)^{*}\end{array}$ \\
\hline Control & 66 & $61(92.4)^{\mathrm{a}}$ & $9(14.8)$ & $50(82.0)$ & $2(3.2)$ \\
Vitrified & 64 & $42(65.6)^{\mathrm{b}}$ & $7(16.7)$ & $33(78.6)$ & $2(4.7)$ \\
\hline
\end{tabular}

ab Significant differences within the same column $(\mathrm{P}<0.05)$. ${ }^{*}$ The percentages were calculated based on the number of fertilized oocytes.

Table 4. In vitro development of immature bovine oocytes after vitrification

\begin{tabular}{|c|c|c|c|c|c|}
\hline Treatment & $\begin{array}{c}\text { Inseminated } \\
n\end{array}$ & $\begin{array}{c}2 \text { cells } \\
n(\%)\end{array}$ & $\begin{array}{c}\text { Blastocysts } \\
n(\%)\end{array}$ & $\begin{array}{c}\text { Total cells } \\
n\end{array}$ & $\begin{array}{c}\text { Apoptotic cells } \\
n\end{array}$ \\
\hline Control & 225 & $190(84.4)^{\mathrm{a}}$ & $78(34.7)^{\mathrm{a}}$ & $92.6 \pm 31.3$ & $2.6 \pm 1.9$ \\
\hline Vitrified & 219 & $122(55.7)^{\mathrm{b}}$ & $5(2.3)^{b}$ & $84.3 \pm 18.9$ & $4.8 \pm 2.9$ \\
\hline
\end{tabular}

ab Significant differences within the same column $(\mathrm{P}<0.05)$.

employing a conventional straw has never reached a satisfactory level. A breakthrough was achieved for bovine oocytes when an approach was proposed that minimizes the vitrified sample to obtain a much faster cooling rate. A significant improvement in bovine oocyte survival was obtained when EM grids were used to provide physical support [12]. Thereafter, OPS [6, 26, 27] and nylon mesh $[14,28]$ were introduced as containers for freezing of immature bovine oocytes. In the present study, bovine immature oocytes were vitrified using the microdrop vitrification method. This method involves dropping an oocyte-containing vitrification solution directly into liquid nitrogen $\left(\mathrm{LN}_{2}\right)$; the success of this method is due to elimination of the insulation effect of the container wall. Warming of the oocytes is equally rapid when vitrified samples are directly dropped into a warm solution [18].

One essential factor in cryosurvival is permeation of a certain amount of cryoprotectant into the oocyte, which increases with the duration of exposure; however, the toxicity of the cryoprotectant must be avoided, with an optimum exposure time being favorable for this purpose. In the present study, we investigated the optimum period for first and second pre-equilibration in vitrification solution before rapid cooling. Two parameters were investigated in this experiment as follows: (i) oocyte maturation after $24 \mathrm{~h}$ of culture and (ii) cytoskeletal damage. Oocyte maturation provides an indication of the overall impairment of oocytes exposed to cryoprotectant with vitrification. Microtubules and microfilaments are critical for meiotic division [29]; the latter play a pivotal role in migration of the MI spindle and extrusion of the first polar body [30]. Disruption of the microtubules increases the frequency of deformed spindle apparatuses [31]. Our experiments showed that a 1 min exposure of the immature bovine oocytes to vitrification solution after $3 \mathrm{~min}$ of first pre-equilibration (3-1 $\mathrm{min}$ ) yielded high rates of oocyte survival and maturation. Study of the microtubules also confirmed that oocytes equilibrated for 3-1 min had the lowest proportion of abnormal configuration.

In the present study, the maturation rate of the vitrified oocytes was lower than that of the fresh oocytes despite a high rate of recovery of morphologically normal oocytes. Examination of the ultrastructure of the immature bovine oocytes after vitrification suggests that freezing damage is associated with destruction of intercellular contact between the cumulus cells and oocyte [27, 32]. The presence of this intercellular contact via a gap junction plays an important role in metabolic cooperation between the oocyte and cumulus cells during the growth phase and final maturation of the oocytes [31]. We believe that the low number of oocytes reaching the MII phase after maturation in the present study was probably due to damage to the gap junctions between cumulus cells and oocytes. 
In the present study, we found that fertilization and embryo development following in vitro fertilization of vitrified oocytes were relatively reduced compared with those in the controls. These findings suggest that despite our efforts to improve the vitrification method, the cooling/ warming procedure negatively affected oocyte developmental competence. The low fertilization and embryo development rates of the vitrified oocytes might be caused by many factors. Oocytes have a relatively complex subcellular structure, and many of the subcellular components in this structure are particularly sensitive to low temperatures [33], osmotic pressure, and ionic strength $[34,35]$. Previous studies have shown that exposure of GV-stage oocytes to cryoprotectants or vitrification significantly reduces normal spindle and chromosome configuration and microfilament distribution after in vitro maturation $[31,36]$. These cytological abnormalities may adversely affect post-fertilization development [31, 37]. In the present study, we also observed high rates of abnormal spindle configuration and microfilament distribution in vitrified GV-stage bovine oocytes after in vitro maturation. Our results showed that the blastocyst rate for vitrified immature bovine oocytes was very low (2.3\%). However, the embryo cleavage rate obtained for the vitrified group $(45.9 \%)$ in our study using immature bovine oocytes was similar to the rate reported by Vieira et al. (49.0\%) [6] after OPS vitrification and was better than the rates reported by LeGal and Massip [38], Matsumoto et al. [28], and Abe et al. [14] after vitrification using OPS (25.6\%), EM grid (7\%), and nylon mesh $(37.7 \%)$, respectively. This result suggests that we achieved a technical advancement for the vitrification methodology for immature bovine oocytes.

In conclusion, our data indicated that immature bovine oocytes vitrified by the microdrop method can survive and subsequently be cultured to mature oocytes capable of undergoing fertilization in vitro and developing into blastocysts. The ease of application of the microdrop technology makes vitrification of immature oocytes an attractive method for cryopreservation. However, further studies should be conducted to increase the rates of embryonic development in vitro.

\section{References}

1. Bos-Mikich A, Wood MJ, Candy CJ, Whittingham DG. Cytogenetical analysis and developmental potential of vitrified mouse oocytes. Biol Reprod 1995; 53: 780-785.

2. Miyake T, Kasai M, Zhu SF, Sakurai T, Machida T. Vitrification of mouse oocytes and embryos at various stages of development in an ethylene glycolbased solution by a simple method. Theriogenology 1993; 40: 121-124.

3. Wood MJ, Barros C, Candy J, Carroll J, Melendez J, Whittingham DG. High rates of survival and fertilization of mouse and hamster oocytes after vitrification in dimethyl sulfoxide. Biol Reprod 1993; 49: 489-495.

4. Kuleshova L, Gianaroli L, Ferraretti A, Trounson A. Birth following vitrification of a small number of human oocytes: case report. Hum Reprod 1999; 14: 3077-3079.

5. Saha S, Rajamahendran R, Boediono A, Sumantri C, Suzuki T. Viability of bovine blastocysts obtained after 7,8 or 9 days of culture in vitro following vitrification and one-step dehydration. Theriogenology 1996; 46: 331-343.

6. Vieira AD, Mezzalira A, Barbieri DP, Lehmkuhl RC, Rubin MI, Vajta G. Calves born after open pulled straw vitrification of immature bovine oocytes. Cryobiology 2002; 45: 91-94.

7. Kuchenmeister U, Kuwayama M. In vitro blastocysts formation after vitrification of immature bovine oocytes. Theriogenology 1997; 47: 348 (Abrstr.).

8. Otoi T, Yamamoto K, Koyama N, Suzuki T. In vitro fertilization and development of immature and mature bovine oocytes cryopreserved by ethylene glycol with sucrose. Cryobiology 1995; 32: 455-460.

9. Suzuki T, Boediono A, Takagi M, Saha S, Sumantri C. Fertilization and development of frozen-thawed germinal vesicle bovine oocytes by a one-step dilution method in vitro. Cryobiology 1996; 33: 515-524.

10. Kubota C, Yang $\mathbf{X}$, Dinnyes A, Todoroki J, Yamakuchi H, Mizoshita K, Inohac S, Tabara N. In vitro survival frozen-thawed bovine oocytes after IVF, nuclear transfer, and parthenogenetic activation. Mol Reprod Dev 1998; 51: 281-286.

11. Vajta G. Vitrification of bovine oocytes and embryos. Embryo Transfer Newsletter 1997; 15: 12-18.

12. Martino A, Songsasen N, Leibo SP. Development into blastocyst of bovine oocytes cryopreserved by ultra-rapid cooling. Biol Reprod 1996; 54: 1059-1069. 
13. Fuchinoue K, Fukunaga N, Chiba S, Nakajo Y, Yagi A, Kyono K. Freezing of human immature oocytes using cryoloops with Taxol in the vitrification solution. J Assist Reprod Genet 2004; 21: 307-309.

14. Abe Y, Hara K, Matsumoto H, Kobayashi J, Sasada H, Ekwall H, Rodiguez-Martinez H, Sato E. Feasibility of a nylon-mesh holder for vitrification of bovine germinal vesicle oocytes in subsequent production of viable blastocysts. Biol Reprod 2005; 72: 1416-1420.

15. Landa V, Tepla O. Cryopreservation of mouse 8-cell embryos in microdrops. Folia Biologica (Praha) 1990; 6: 153-158.

16. Riha J, Landa V, Kneissl J, Matus J, Jindra J, Kloucek Z. Vitrification of cattle embryos by direct dropping into liquid nitrogen and embryo survival after nonsurgical transfer. Zivoc Vyr 1991; 36: 113119.

17. Yang BS, Leibo SP. Viability of in vitro-derived bovine zygotes cryopreserved in microdrops. Theriogenology 1999; 51: 178 (Abrstr.).

18. Papis K, Shimizu M, Izaike Y. Factors affecting the survivability of bovine oocytes vitrified in droplets. Theriogenology 2000; 54: 651-658.

19. Parrish JJ, Susko-Parrish J, Winer MA, First NL. Capacitation of bovine sperm by heparin. Biol Reprod 1988; 38: 1171-1180.

20. Bavister BD, Yanagimachi R. The effects of sperm extracts and energy sources on the motility and acrosome reaction of hamster spermatozoa in vitro. Biol Reprod 1977; 16: 228-237.

21. Wang S, Liu Y, Holyoak GR, Bunch TD. The effects of bovine serum albumin and fetal bovine serum on the development of pre- and postcleavage-stage bovine embryos cultured in modified CR2 and M199 media. Anim Reprod Sci 1997; 48: 37-45.

22. Cai XY, Chen GA, Lian Y, Zheng XY, Peng HM. Cryoloop vitrification of rabbit oocytes. Hum Repord 2005; 20: 1969-1974.

23. Hamano S, Koikeda A, Kuwayama M, Nagai T. Full-term development of in vitro-matured, vitrified and fertilized bovine oocytes. Theriogenology 1992; 38: 1085-1090.

24. Fuku E, Kojima T, Shioya Y, Marcus GJ, Downey BR. In vitro fertilization and development of frozenthawed bovine oocytes. Cryobiology 1992; 29: 485492.

25. Hochi S, Ito K, Hirabayashi M, Ueda M, Kimura K, Hanada A. Effect of nuclear stages during IVM on the survival of vitrified-warmed bovine oocytes. Theriogenology 1998; 49: 787-796.

26. Hurrt AE, Landim-Alvarenga F, Seidel GE, Squires EI. Vitrification of immature and mature equine and bovine oocytes in an ethylene glycol, ficoll and sucrose solution using open pulled straws. Theriogenology 2000; 54: 119-128.

27. Diez C, Duque P, Gomez E, Hidalgo CO, Tamargo C, Rodriguez A, Fernandez L, de la Varga S, Fernandez A, Facal N, Carbajo M. Bovine oocyte vitrification before or after meiotic arrest: effects on ultrastructure and development ability. Theriogenology 2005; 64: 317-333.

28. Matsumoto H, Jiang JY, Tanaka T, Sasada H, Sato E. Vitrification of large quantities of immature bovine oocytes using nylon mesh. Cryobiology 2001; 42: 139-144.

29. Brunet S, Pahlavan G, Taylor S, Maro B. Functionality of the spindle checkpoint during the first meiotic division of mammalian oocytes. Reproduction 2003; 126: 443-450.

30. Gallicano GI. Composition, regulation and function of the cytoskeleton in mammalian eggs and embryos. Frontier Biosci 2001; 6: 1089-1108.

31. Rojas C, Palomo MJ, Albarracin JL, Mogas T. Vitrification of immature and in vitro matured pig oocytes: study of distribution of chromosomes, microtubules, and actin microfilaments. Cryobiology 2004; 49: 211-220.

32. Fuku E, Xia L, Downey BR. Ultrastructural changes in bovine oocytes cryopreserved by vitrification. Cryobiology 1995; 32: 139-156.

33. Magistrini M, Szollosi D. Effects of cold and of isopropyl-N-phenylcarbamate on the second meiotic spindle of mouse oocytes. Ear J Cell Biol 1980; 22: 699-707.

34. McWilliams RB, Gibbons WE, Leibo SP. Osmotic and physiological responses of mouse zygotes and human oocytes to mono- and di-saccharides. Hum Reprod 1995; 10: 1163-1171.

35. Stachecki JJ, Cohen J, Willadsen S. Detrimental effects of sodium during mouse oocyte cryopreservation. Biol Reprod 1998; 59: 395-400.

36. Isachenko EF, Nayudu PL. Vitrification of mouse germinal vesicle oocytes: effect of treatment temperature and egg yolk on chromatin and spindle normality and cumulus integrity. Hum Reprod 1999; 14: 400-408.

37. Park S, Son W, Lee S, Lee K, Ko J, Cha K. Chromosome and spindle configuration of human oocytes matured in vitro after cryopreservation at germinal vesicle stage. Fertil Steril 1997; 68: 920-926.

38. LeGal F, Massip A. Development of thawed oocytes fertilized in vitro after vitrification by the open pulled straw method before or after in vitro maturation. In: Lauria A (ed.), Gametes: Development and function. Rome: Serono Symposia; 1998: 554. 